\title{
Analisa Algoritma Profile Matching dalam Menentukan Anggota Security Terbaik di PTPN IV Unit Usaha Marjandi
}

\author{
Oi Ramadani Sinurat ${ }^{1}$, Eka Irawan ${ }^{2}$, Rafiqa Dewi ${ }^{3}$, Sundari Retno Andani ${ }^{4}$, M.Fauzan $^{5}$ \\ STIKOM Tunas Bangsa, Pematangsiantar, Indonesia1,2,3,4,5 \\ Jln. Jenderal Sudirman Blok A No.1/2/3 Pematangsiantar, Indonesia \\ oiramadanisinurat@gmail.com
}

\begin{abstract}
Security is a group of officers formed by agencies / projects / business entities to carry out physical security in the context of self-supporting security in their work environment. In the selection of the best security in Marjandi plantations still use the performance class data. This study discusses determining the best security member in PTPN IV marjandi business unit Data sources used from the Marjandi Business Unit PTPN IV office. This study uses the Decision Support System (SPK) technique in the data processing process using Profile matching method. Profile matching method is a mechanism for decision making by assuming that there is an ideal target value that must be met by the subject under study, rather than the minimum level that must be met or passed. The purpose of this study is to help the management to make it easier to do the best security selection at the Marjandi PTPN IV business unit.
\end{abstract}

Keywords: Security, Decision Support Systems, Profile Matching

Abstrak-Security adalah satuan kelompok petugas yang dibentuk oleh instansi/proyek/badan usaha untuk melakukan keamanan fisik (physical security) dalam rangka penyelenggaraan keamanan swakarsa di lingkungan kerjanya. Dalam pemilihan Security terbaik diPerkebunan Marjandi masih menggunakan data golongan kinerja tersebut. Penelitian ini membahas menentukan anggota Security terbaik di PTPN IV Unit Usaha Marjandi. Sumber data yang digunakan dari kantor PTPN IV Unit Usaha Marjandi. Penelitian ini menggunakan teknik Sistem Pendukung Keputusan (SPK) dalam proses pengolahan data dengan metode Profile matching. Metode Profile matching merupakan suatu mekanisme pengambilan keputusan dengan mengasumsikan bahwa terdapat nilai target yang ideal yang harus dipenuhi oleh subjek yang diteliti, bukannya tingkat minimal yang harus dipenuhi atau dilewati. Tujuan dari penelitian ini ialah untuk membantu pihak management agar lebih mudah dalam melakukan pemilihan security terbaik di PTPN IV Unit Usaha Marjandi.

Kata Kunci : Security, Sistem Pendukung Keputusan, Profile Matching

\section{PENDAHULUAN}

Pemilihan Security terbaik dari berbagai candidate security lainnya menjadi acuan yang objektif untuk menentukan seorang security terbaik. Rekomendasi dari pimpinan atau rekan kerja untuk menilai security yang akan menjadi security terbaik bukan suatu jaminan dan masih bersifat subjektif. Perlu ada perubahan cara dan metode sebagai alternatif pemilihan Security yang sesuai dengan kebutuhan. Dalam penelitian kali ini metode Profile Matching menjadi pilihan guna memberikan penilaian dan evaluasi kinerja security untuk dipromosikan menjadi yang terbaik. Ada beberapa aspek dalam melakukan penilaian dan evaluasi tersebut, yaitu aspek Sikap Kinerja dan Aspek Prilaku. Aspek sikap kerja memiliki unsur Jabatan, Wawasan, Kreatifitas. Terakhir aspek Perilaku meliputi Disiplin, 
Kepemimpinan, Kerjasama, Sikap. Dalam pemilihan security terbaik di Perkebunan Marjandi masih saja melihat dari segi golongan pekerjaan sehingga tidak objektif dan tidak akurat dalam melakukan sebuah pemilihan security terbaik tersebut. Dalam hal ini penulis merekomendasikan sebuah algoritma profile matching dalam melakukan sebuah pemilihan security terbaik tersebut, supaya dalam pemilihan security tersebut bisa lebih objektif dan akurat.

Sistem Pendukung keputusan sangat penting dalam membuat keputusan, supaya keputusan tersebut dipilih secara benar dan tepat agar nantinya dapat mengambil personel yang ideal. Penelitian sebelumnya yang berjudul Sistem Pendukung Keputusan pemilihan menentukan starting five tim futsal Menggunakan Metode Profile Matching. Penerapan dengan menggunakan metode profile matching. Profile matching merupakan salah satu bagian dari Multicriteria decision making yang mengandung unsur objektif dan tujuan [1]. Metode profile matching dapat digunakan untuk menyelesaikan masalah semi terstruktur seperti pemilihan Security terbaik diPTPN IV unit usaha Marjandi, dalam permasalahan ini pemilihan personel masih bersifat manual dan bernilai subjectif atau prosedur standar yang biasa digunakan belum mampu mengatasi permasalahan tersebut. Implementasi Metode profile matching pada pemilihan Security terbaik diPTPN IV unit usaha Marjandi,untuk Menganalisa pengambilan keputusan yang mempermudah Pihak management dalam menyeleksi Anggota Security Terbaik dalam menentukan personel yang ideal sesuai dengan aspek-aspek penilaian yang telah ditentukan

\section{METODOLOGI PENELITIAN}

Dalam penelitian ini metode penenlitian yang dilakukan memiliki beberapa tahapan yaitu pengumpulan data, analisa data, perancangan sistem, implementasi sistem, pengujian dan pengambilan kesimpulan. Penelitian ini dilakukan untuk mengimplementasikan metode profile matching guna mendapatkan sebuah model aturan pada kualitas dalam melakukan pemilihan security terbaik di Unit Usaha Marjandi

\subsection{Sistem Pendukung Keputusan Sistem}

Pendukung Keputusan (Decision Support Systems) adalah sebuah sistem yang dimaksudkan untuk mendukung parapengambil keputusan manajerial dalam situasi keputusan semiterstruktur.[2]

\subsection{Metode Profile Matching}

Profile matching merupakan suatu mekanisme pengambilan keputusan dengan mengasumsikan bahwa terdapat nilai target yang ideal yang harus dipenuhi oleh subjek yang diteliti, bukannya tingkat minimal yang harus dipenuhi atau dilewati. Dalam proses profile matching secara garis besar merupakan proses membandingkan antara kompetensi individu kedalam kompetensi jabatan sehingga dapat diketahui perbedaan kompetensinya (disebut juga gap), semakin kecil gap yang dihasilkan maka bobot nilainya semakin besar yang berarti memiliki peluang lebih besar untuk individu menempati posisi tersebut.[3]. Penyelesaian Algoritma metode profile matching memiliki konsep yaitu[3] : 
1. Langkah 1 : Mendefinisikan terlebih dahulu kriteria-kriteria yang akan di jadikan sebagai tolak ukur penyelesaian masalah dan menentukan skala prioritas dari masing-masing kriteria (profil kriteria).

2. Langkah 2 : Menghitung Nilai GAP dan Mapping GAP

3. Langkah 3 : Menghitung Nilai Rata-rata Core factor dan Nilai Rata secondary factor yaitu sebagai berikut:

$$
\begin{aligned}
& \mathrm{NCF}=\frac{\sum N C}{\sum I C} \\
& \mathrm{NSF}=\frac{\sum N S}{\sum I S}
\end{aligned}
$$

Dimana:

NCF: Nilai Rata-rata Core Factor

NSF : Nilai Rata-rata Secondary Factor

NC : Jumlahl Total Nilai Core Factor

IC : Jumlahl Total Nilai item Core Factor

NS : Jumlahl Total Nilai Secondary Factor

IS : Jumlah Total Nilai item Secondary Factor

4. Langkah 4 : Melakukang Perengkingan

\section{HASIL DAN PEMBAHASAN}

\subsection{Penyelesaian Metode Profile Matching}

Penelitian ini merupakan penelitian kualitatif dengan rancangan studikasus, Pendekatan kualitatif digunakan dalam penelitian ini untuk mendeskripsikan bagaimana penggunaan profile matching di perguruantinggi[4]. Perhitungan dalam Metode Profile Matching akan dijelaskan mulai dari proses perhitungan bobot setiap aspek criteria sampai perhitungan nilai akhir yang digunakan untuk penganbilan keputusan. Contoh: Berikut ini adalah sampel data kriteria dan bobot kriteria sebagai berikut:

\begin{tabular}{|c|c|c|c|c|c|}
\hline $\begin{array}{l}\mathrm{N} \\
\mathrm{o} .\end{array}$ & Nama Kriteria & Presentase & $\begin{array}{c}\text { NilaiBobot Sub } \\
\text { Kriteria }\end{array}$ & Type & NilaiPersen \\
\hline \multirow[t]{4}{*}{1.} & Sasaran kerja & \multirow[t]{4}{*}{$70 \%$} & & & \\
\hline & - Tugas Jabatan & & 5 & Core & \multirow[t]{2}{*}{$60 \%$} \\
\hline & Wawasan & & 3 & Core & \\
\hline & - kreatifitas & & 4 & Secondary & $40 \%$ \\
\hline \multirow[t]{5}{*}{2.} & Prilaku & \multirow[t]{5}{*}{$30 \%$} & & & \\
\hline & - Disiplin & & 4 & Core & \multirow[t]{2}{*}{$60 \%$} \\
\hline & - kepemimpinan & & 4 & Core & \\
\hline & - Kerjasama & & 3 & Secondary & \multirow[t]{2}{*}{$40 \%$} \\
\hline & - Sikap & & 3 & Secondary & \\
\hline
\end{tabular}

Tabel 1. Sampel Data Kriteria

\section{Langkah 1:}

a. Nilai Aspek

Berikut adalah Tabel Nilai Aspek algoritma Profile Matching dalam menentukan Security terbaik

Tabel 2. Nilai Aspek

\begin{tabular}{|l|l|l|}
\hline Nilai Kriteria & 1 & Tidak memenuhi syarat \\
\hline
\end{tabular}


b. Penilaian

\begin{tabular}{|l|c|c|}
\hline & 2 & Kurang \\
\cline { 2 - 3 } & 3 & Cukup \\
\cline { 2 - 3 } & 4 & Baik \\
\cline { 2 - 3 } & 5 & Sangat Baik \\
\hline
\end{tabular}

Berikut adalah Tabel Penilaian algoritma Profile Matching dalam menentukan Security terbaik;

Tabel 3. Penilaian

\begin{tabular}{|c|c|c|c|c|c|c|c|c|}
\hline \multirow{2}{*}{ No } & Nama Pegawai & \multicolumn{3}{|c|}{ Sasaran Kerja } & \multicolumn{4}{|c|}{ Prilaku } \\
\cline { 3 - 9 } & & A1 & A2 & A3 & B1 & B2 & B3 & B4 \\
\hline 1 & Alternatif 1 & 5 & 3 & 4 & 5 & 4 & 4 & 2 \\
\hline 2 & Alternatif 2 & 5 & 3 & 4 & 4 & 5 & 4 & 3 \\
\hline
\end{tabular}

Langkah 2:

a. Menentukan Gap

1. Sasaran Kerja

Berikut adalah rumus dalam menentukan Gap Sasaran Kerja;

gap= Profil Pegawai

2. Profile Kinerja

Keterangan:

Profil Pegawai : Nilai Pegawai

Profil Kinerja : Nilai Standart

Berikut adalah Tabel Aspek Sasaran Kerja algoritma Profile Matching dalam menentukan Security terbaik;

Tabel 4. Aspek Sasaran Kerja

\begin{tabular}{|c|c|c|c|c|}
\hline \multirow{2}{*}{ No } & Nama Pegawai & \multicolumn{3}{|c|}{ Sasaran Kerja } \\
\cline { 3 - 5 } & & A1 & A2 & A3 \\
\hline 1 & Alternatif 1 & 5 & 3 & 4 \\
\hline 2 & Alternatif 2 & 5 & 3 & 4 \\
\hline \multicolumn{2}{|c|}{ Profile Pencapaian } & 5 & 3 & 4 \\
\hline 1 & Alternatif 1 & 0 & 0 & 0 \\
\hline 2 & Alternatif 2 & 0 & 0 & 0 \\
\hline
\end{tabular}

3. Prilaku

Berikut adalah rumus dalam menentukan Gap Aspek Prilaku;

gap= Profile Pegawai - Profile Kinerja

Keterangan:

Profil Pegawai : Nilai Pegawai

Profil Kinerja : Nilai Standart

Berikut adalah Tabel Aspek Prilaku algoritma Profile Matching dalam menentukan Security terbaik;

Tabel 5. Aspek Prilaku

\begin{tabular}{|c|c|c|c|c|c|}
\hline \multirow{2}{*}{ No } & Nama Pegawai & \multicolumn{4}{|c|}{ Prilaku } \\
\cline { 3 - 6 } & & B1 & B2 & B3 & B4 \\
\hline 1 & Alternatif 1 & 5 & 4 & 4 & 2 \\
\hline 2 & Alternatif 2 & 4 & 5 & 4 & 3 \\
\hline \multicolumn{2}{|c|}{ Profile Pencapaian } & 4 & 4 & 3 & 3 \\
\hline 1 & Alternatif 1 & 1 & 0 & 1 & -1 \\
\hline 2 & Alternatif 2 & 0 & 1 & 1 & 0 \\
\hline
\end{tabular}


4. Nilai Bobot

Berikut adalah Tabel Nilai Bobot algoritma Profile Matching dalam menentukan Security terbaik;

Tabel 6. Nilai Bobot

\begin{tabular}{|c|c|c|c|}
\hline No & Selisih & Nilai Bobot & Keterangan \\
\hline 1 & 0 & 5 & Tidak Ada Selisih \\
\hline 2 & 1 & 4,5 & Kompeten Individu Kelebihan 1 Tingkat Level \\
\hline 3 & -1 & 4 & Kompeten Individu Kekurangan 1 Tingkat Level \\
\hline 4 & 2 & 3,5 & Kompeten Individu Kelebihan 2 Tingkat Level \\
\hline 5 & -2 & 3 & Kompeten Individu Kekurangan 2 Tingkat Level \\
\hline 6 & 3 & 2,5 & Kompeten Individu Kelebihan 3 Tingkat Level \\
\hline 7 & -3 & 2 & Kompeten Individu Kekurangan 3 Tingkat Level \\
\hline 8 & 4 & 1,5 & Kompeten Individu Kelebihan 4 Tingkat Level \\
\hline 9 & -4 & 1 & Kompeten Individu Kekurangan 4 Tingkat Level \\
\hline
\end{tabular}

\section{Penentuan Nilai Bobot}

Berikut adalah Tabel Penentuan Nilai Bobot Aspek Sasaran Kerja algoritma Profile Matching dalam menentukan Security terbaik;

Tabel 7. Nilai Bobot Aspek Sasaran Kerja

\begin{tabular}{|c|c|c|c|c|}
\hline \multirow{2}{*}{ No } & Nama Pegawai & \multicolumn{3}{|c|}{ Sasaran Kerja } \\
\cline { 3 - 5 } & & A1 & A2 & A3 \\
\hline 1 & Alternatif 1 & 0 & 0 & 0 \\
\hline 2 & Alternatif 2 & 0 & 0 & 0 \\
\hline \multicolumn{5}{|c|}{ Nilai Bobot } \\
\hline 1 & Alternatif 1 & 5 & 5 & 5 \\
\hline 2 & Alternatif 2 & 5 & 5 & 5 \\
\hline
\end{tabular}

Berikut adalah Tabel Penentuan Nilai Bobot Aspek Prilaku algoritma Profile Matching dalam menentukan Security terbaik;

Tabel 8. Penentuan Nilai Bobot Aspek Prilaku

\begin{tabular}{|c|c|c|c|c|c|}
\hline No & Nama Pegawai & \multicolumn{5}{|c|}{ Prilaku } \\
\cline { 3 - 6 } & & B1 & B2 & B3 & B4 \\
\hline 1 & Alternatif 1 & 1 & 0 & 1 & -1 \\
\hline 2 & Alternatif 2 & 0 & 1 & 1 & 0 \\
\hline \multicolumn{7}{|c|}{ Nilai bobot } \\
\hline 1 & Alternatif 1 & 4,5 & 5 & 4,5 & 4 \\
\hline 2 & Alternatif 2 & 5 & 4,5 & 4,5 & 5 \\
\hline
\end{tabular}

Langkah 3:

a. Perhitungan Aspek Sasaran Kerja

Berikut adalah Beberapa Perhitungan Aspek Sasaran Kerja algoritma Profile Matching dalam menentukan Security terbaik;

$$
\begin{array}{ll}
\mathrm{A} 1=\mathrm{NCF} & =\frac{5+5}{2}=5 \\
\mathrm{NSF} & =\frac{5}{1}=5 \\
\mathrm{~A} 2=\mathrm{NCF} & =\frac{5+5}{2}=5
\end{array}
$$


$\mathrm{NSF} \quad=\frac{5}{1}=5$

Dan Seterusnya sampai A10 sehingga dapat hasil bobot nilai gap aspek sasaran kerja.

Berikut adalah Tabel Bobot Nilai Gap Aspek Sasaran Kerja algoritma Profile Matching dalam menentukan Security terbaik;

\section{Tabel 9. Bobot Nilai Gap Aspek Sasaran Kerja}

\begin{tabular}{|c|c|c|c|c|c|c|}
\hline \multirow[t]{2}{*}{ No } & \multirow[t]{2}{*}{ Nama Pegawai } & \multicolumn{3}{|c|}{ Kriteria } & \multirow[t]{2}{*}{ NCF } & \multirow[t]{2}{*}{ NSF } \\
\hline & & $\mathrm{A} 1$ & A2 & $\mathrm{A} 3$ & & \\
\hline 1 & Alternatif 1 & 5 & 5 & 5 & 5 & 5 \\
\hline 2 & Alternatif 2 & 5 & 5 & 5 & 5 & 5 \\
\hline
\end{tabular}

b. Perhitungan Aspek Prilaku

Berikut adalah beberapa Perhitungan Aspek Prilaku algoritma Profile Matching dalam menentukan Security terbaik;

$\mathrm{A} 1=\mathrm{NCF} \quad=\frac{4,5+5}{2}=4,75$

$\mathrm{NSF} \quad=\frac{4,5+4}{2}=4,25$

$\mathrm{A} 2=\mathrm{NCF} \quad=\frac{5+4,5}{2}=4,75$

NSF $\quad=\frac{4,5+5}{2}=4,75$

Dan Seterusnya sampai A10 sehingga dapat hasil bobot nilai gap aspek prilakunya.

Berikut adalah Tabel Bobot Nilai Gap Aspek Prilaku algoritma Profile Matching dalam menentukan Security terbaik;

Tabel 10. Bobot Nilai Gap Aspek Prilaku

\begin{tabular}{|c|c|c|c|c|c|c|c|}
\hline \multirow[t]{2}{*}{ No } & \multirow[t]{2}{*}{ Nama Pegawai } & \multicolumn{4}{|c|}{ Prilaku } & \multirow[t]{2}{*}{$\mathrm{NCF}$} & \multirow[t]{2}{*}{ NSF } \\
\hline & & B1 & B2 & B3 & B4 & & \\
\hline 1 & Alternatif 1 & 4,5 & 5 & 4,5 & 4 & 4,75 & 4,25 \\
\hline 2 & Alternatif 2 & 5 & 4,5 & 4,5 & 5 & 4,75 & 4,75 \\
\hline
\end{tabular}

c. Perhitungan Nilai Total Sasaran Kerja

Berikut adalah Perhitungan Nilai Total Sasaran Kerja algoritma Profile Matching dalam menentukan Security terbaik;

$\mathrm{N}(\mathrm{s} . \mathrm{p})=(\mathrm{x}) \% \mathrm{NCF}(\mathrm{s} . \mathrm{p})+(\mathrm{x}) \% \mathrm{NSF}(\mathrm{s.p})$

Keterangan:

N(s.p) = Nilai Total dari Aspek

NCF(s.p) = Nilai Rata-rata Core Factor (Sasaran Kerja, Prilaku)

NSF(s.p) = Nilai Rata-rata Secoundary Factor (Sasaran Kerja, Prilaku)

$(\mathrm{x}) \%=$ Nilai persen yang diinputkan

$$
\begin{aligned}
\mathrm{A} 1 & =(60 \% * 5)+(40 \% * 5) \\
& =3+2 \\
& =5 \\
\mathrm{~A} 2 & =(60 \% * 5)+(40 \% * 5) \\
& =3+2 \\
& =5
\end{aligned}
$$


Dan Seterusnya sampai A10 sehingga dapat hasil nilai total aspek sasaran kerjanya.

Berikut adalah Tabel Nilai Total Aspek Sasaran Kerja algoritma Profile Matching dalam menentukan Security terbaik;

Tabel 11 Nilai Total Aspek Sasaran Kerja
\begin{tabular}{|c|c|c|c|c|}
\hline No & Nama Pegawai & NCF & NSF & N(a) \\
\hline 1 & Alternatif 1 & 5 & 5 & 5 \\
\hline 2 & Alternatif 2 & 5 & 5 & 5 \\
\hline
\end{tabular}

d. Perhitungan Nilai total aspek Prilaku

Berikut adalah Perhitungan Nilai total aspek Prilaku algoritma Profile Matching dalam menentukan Security terbaik;

$\mathrm{N}(\mathrm{s} . \mathrm{p})=(\mathrm{x}) \% \mathrm{NCF}(\mathrm{s} . \mathrm{p})+(\mathrm{x}) \% \mathrm{NSF}(\mathrm{s} . \mathrm{p})$

Keterangan:

N(s.p) = Nilai Total dari Aspek

NCF(s.p) = Nilai Rata-rata Core Factor (Sasaran Kerja, Prilaku)

$\mathrm{NSF}$ (s.p) = Nilai Rata-rata Secoundary Factor (Sasaran Kerja, Prilaku)

$(\mathrm{x}) \%=$ Nilai persen yang diinputkan

$$
\begin{aligned}
\mathrm{A} 1 & =(60 \% * 4,75)+(40 \% * 4,25) \\
& =2,85+1,7 \\
& =4,55 \\
\mathrm{~A} 2 & =(60 \% * 4,75)+(40 \% * 4,75) \\
& =2,85+1,9 \\
& =4,75
\end{aligned}
$$

Dan Seterusnya sampai A10 sehingga dapat hasil nilai total aspek prilakunnya.

Berikut adalah Tabel Nilai Total Aspek Prilaku algoritma Profile Matching dalam menentukan Security terbaik;

Tabel 12 Nilai Total Aspek Prilaku

\begin{tabular}{|c|c|c|c|c|}
\hline No & Nama Pegawai & NCF & NSF & N(b) \\
\hline 1 & Alternatif 1 & 4,75 & 4,25 & 4,55 \\
\hline 2 & Alternatif 2 & 4,75 & 4,75 & 4,75 \\
\hline
\end{tabular}

e. Penentuan Hasil Akhir Penelitian

Berikut adalah Perhitungan Penentuan Hasil Akhir Penelitian algoritma Profile Matching dalam menentukan Security terbaik;

$\mathrm{HA}=(\mathrm{x}) \% \mathrm{Ns}+(\mathrm{x}) \% \mathrm{~Np}$

Keterangan :

HA : Hasil Akhir

Ns : Nilai sasaran kerja 
$\mathrm{Np}$ : Nilai Prilaku

(x)\%: Nilai persen yang diinput

Alternatif $1=(70 \% * 5)+(30 \% * 4,55)=4,865$

Alternatif $2=(70 \% * 5)+(30 \% * 4,75)=4,925$

Dan Seterusnya sampai A10 sehingga dapat hasil Rangkingnya.

Langkah 4:

Berikut adalah Tabel Ranking algoritma Profile Matching dalam menentukan Security terbaik;

Tabel 13. Ranking

\begin{tabular}{|c|c|c|c|c|c|}
\hline No & Nama Pegawai & $\mathrm{N}(\mathrm{a})$ & $\mathrm{N}(\mathrm{b})$ & Hasil Akhir & Ranking \\
\hline 1 & Alternatif 1 & 5 & 4,55 & 4,865 & 2 \\
\hline 2 & Alternatif 2 & 5 & 4,75 & 4,925 & 1 \\
\hline 3 & Alternatif 3 & 3,95 & 4,35 & 4,07 & 10 \\
\hline 4 & Alternatif 4 & 4,4 & 4,85 & 4,535 & 7 \\
\hline 5 & Alternatif 5 & 4,45 & 4,65 & 4,51 & 8 \\
\hline 6 & Alternatif 6 & 4,45 & 4,75 & 4,54 & 6 \\
\hline 7 & Alternatif 7 & 4,6 & 4,9 & 4,69 & 5 \\
\hline 8 & Alternatif 8 & 4,55 & 4,1 & 4,415 & 9 \\
\hline 9 & Alternatif 9 & 4,85 & 4,9 & 4,865 & 3 \\
\hline 10 & Alternatif 10 & 5 & 4,5 & 4,85 & 4 \\
\hline
\end{tabular}

\section{KESIMPULAN}

Sistem pendukung keputusan dalam menentukan anggota security terbaik dengan menggunakan algoritma profile matching memiliki beberapa kesimpulan, yaitu :

a. Dengan adanya sistem ini kantor Unit Usaha Marjandi dapat terbantu dalam mengolah data prangkingan.

b. Dalam menentukan anggota security terbaik di kantor Unit Usaha Marjandi dapat diselesaikan dengan metode Profile Matching

c. Sistem memberikan solusi rekomendasi kepada pengguna sesuai dengan kriteria dan bobot yang ditentukan.

d. Sistem yang bdibangun hanyalah sebagai alat bantu untuk memberikan informasi kepada pimpinansebagai bahan pertimbangan dalam mengambil keputusan.

\section{DAFTAR PUSTAKA}

[1] A. Sudarmadi and E. Santoso, "Sistem Pendukung Keputusan Pemilihan Personel Homeband Universitas Brawijaya Menggunakan Metode Profile Matching," vol. 1, no. 12, pp. 17881796, 2017.

[2] S. Kasus, I. Kemasan, S. Gresik, and A. L. Belakang, "Sistem Pendukung Keputusan Kenaikan Jabatan Menggunakan Metode Profile Matching,” pp. 48-55, 2013.

[3] N. A. Irsali, P. Studi, M. Informatika, F. I. Terapan, U. Telkom, and P. Matching, "SISTEM PENDUKUNG KEPUTUSAN DENGAN METODE PROFILE MATCHING UNTUK MENENTUKAN STARTING FIVE TIM FUTSAL ( STUDI KASUS : TIM FUTSAL FC GRAPS FUTSAL ) DECISION SUPPORT SYSTEM WITH MATCHING PROFILE METHOD FOR DETERMINING THE STARTING FIVE FUTSAL TEAM (CASE STUD,” vol. 3, no. 3, pp. 1206-1215, 2017.

[4] S. Pendukung and K. Evaluasi, "Sistem pendukung keputusan evaluasi kinerja mahasiswa dengan metode profile," vol. 10, no. 1, pp. 1180-1188, 2016. 